\title{
Inhibition Behavior of Chitooligosaccharide Derivatives for Carbon Steel in 3.5\% NaCl Solution
}

\author{
Fubin Ma ${ }^{1,2, *}$, Yan Zhang ${ }^{3}$, Hongjuan Wang ${ }^{4}$,Weihua Li $^{1,2}$, Baorong Hou ${ }^{1,2}$ \\ ${ }^{1}$ Institute of Oceanology, Chinese Academy of Sciences, Qingdao 266071, China \\ ${ }^{2}$ Open studio for marine Corrosion and Protection, Qingdao National Laboratory for Marine Science \\ and Technology, Qingdao 266200, China \\ ${ }^{3}$ China Electric Power Research Institute, Beijing 100192, China \\ ${ }^{4}$ Sinopec PSTC Cangzhou Oil Transportion Department, Cangzhou, 061000, China \\ *E-mail: $\underline{\text { mfb281@163.com }}$
}

doi: $10.20964 / 2018.01 .17$

Received: 21 August 2017 / Accepted: 24 October 2017 / Online Published: 1 December 2017

\begin{abstract}
Chitooligosacharide derivatives with different carboxymethylation degrees and grafting degrees of Schiff base were synthesized. Their inhibition property for carbon steel in $3.5 \% \mathrm{NaCl}$ was tested by weight loss measurement, electrochemical measurements. The corrosion morphology of the specimens was examined by scanning electron microscope (SEM). The inhibition mechanism was analyzed by adsorption isotherm fitting and quantum chemical calculation. The results indicated that carboxymethylation improved the inhibition effect by increasing the compounds' solubility; while grafting of Schiff base increased the amount of effective active groups directly but had bad effect on the solubility. The molecules adsorbed on the carbon steel surface by physisorption and chemiadsorption according to Temkin adsorption isotherm and acted as a mixed type inhibitor.
\end{abstract}

Keywords: Chitooligosacharide, carboxymethylation, grafting degree, electrochemical measurements, Temkin adsorption

\section{$\underline{\text { FULL TEXT }}$}

(C) 2018 The Authors. Published by ESG (www.electrochemsci.org). This article is an open access article distributed under the terms and conditions of the Creative Commons Attribution license (http://creativecommons.org/licenses/by/4.0/). 